\title{
Analisis Penerimaan Aplikasi Web Engineering Pelayanan Pengaduan Masyarakat Menggunakan Technology Acceptance Model
}

\author{
${\text { Suaidah*1, }{ }^{*} \text { athifah }}^{2}$ \\ 1,2 Universitas Teknokrat Indonesia; Jl. H.ZA Pagaralam, No 9-11, Labuhanratu, \\ Bandarlampung, (0721) 702022 \\ e-mail: *11 suaidah@teknokrat.ac.id, ${ }^{2}$ lathifah@teknokrat.ac.id
}

\begin{abstract}
Abstrak
P2TP2A-LIP adalah lembaga layanan perempuan dan anak yang dirancang untuk memenuhi informasi dan kebutuhan di bidang pendidikan, kesehatan, ekonomi, politik, hukum, perlindungan dan pencegahan kekerasan terhadap perempuan dan anak serta perdagangan manusia. Sebagai salah satu sarana pelayanan publik, P2TP2A belum menerapkan teknologi informasi untuk memberikan pelayanan, yaitu pengelolaan pengaduan masyarakat, pengelolaan informasi, pelayanan konsultasi, dan penguluhan kepada masyarakat. Sistem pada P2TP2A sebelumnya masih bersifat konvensional dalam proses pengelolaan pengaduan masyarakat, maka perlu diketahui seberapa besar penerimaan sistem baru berbasis teknologi informasi pada masyarakat dan pegawai di P2TP2A dalam menggunakan aplikasi web engineering agar dapat berfungsi secara maksimal. Penelitian ini bertujuan untuk menganalisis penerimaan aplikasi web engineering pelayanan pengaduan masyarakat menggunakan pendekatan TAM. Pada pendekatan technology acceptance model (TAM) terdapat beberapa faktor yang dinilai yaitu persepsi kegunaan dan persepsi kemudahan penggunaan yang didapat dari hasil kuesioner yang diberikan ke responden. Hasil dari penelitian ini akan menunjukkan faktor yang mempengaruhi penerimaan serta bagaimana penerimaan masyarakat terhadap aplikasi web engineering pelayanan pengaduan masyarakat pada P2TP2A.
\end{abstract}

Kata kunci-Pengaduan, Pelayanan Masyarakat, Web Engineering, Technology Acceptance Model

\begin{abstract}
P2TP2A-LIP is a women's and children's service institution designed to meet information and needs in the fields of education, health, economy, politics, law, protection and prevention of violence against women and children and human trafficking. As one of the public service facilities, P2TP2A has not implemented information technology to provide services, namely management of public complaints, management of information, consulting services, and outreach to the public. The system in P2TP2A previously was still conventional in the process of managing public complaints, so it is necessary to know how much the acceptance of the new information technology-based system in the public and employees at P2TP2A in using web engineering applications so that it can function optimally. This study aims to analyze the acceptance of a public complaint service web engineering application using the TAM approach. In the TAM approach, there are several factors that are assessed, namely the perceived usefulness and perceived ease of use obtained from the results of the questionnaire given to respondents. The results of this study will show the factors that influence acceptance and how the public's acceptance of the web engineering application for public complaint services at P2TP2A.
\end{abstract}

Keywords-Complaint, Public Service,Web Engineering, Technology Acceptance Model 


\section{PENDAHULUAN}

$\mathrm{P}$ eranan teknologi informasi melalui komputer di segala bidang membutuhkan penanganan yang lebih teliti, akurat dan detail, sudah menjadi pedoman dari perkembangan kebutuhan akan informasi itu sendiri. Pengaruh teknologi informasi yang begitu besar dalam berbagai aspek kehidupan, baik secara individu maupun institusi. Pada perkembangan teknologi informasi tidak hanya berpengaruh pada bidang komunikasi tetapi juga dalam hal pengambilan keputusan melalui otomatisasi dan kecepatan dalam pemrosesan data yang berada pada tahap selanjutnya akan mempengaruhi layanan (service). Layanan ini sangat membantu dalam meningkatkan kinerja pemerintah di kegiatan pelayanan publik yang optimal. Dalam melaksanakan optimalisasi pelayanan publik diperlukan teknologi yang memungkinkan bentuk akhir dari sebuahh aplikasi komputer adalah berupa layanan yang menjalankan suatu tugas atau proses khusus yang dikenal sebagai web-service.[1] Website merupakan media kumpulan informasi dari halaman web yang menjadi bagiannya nama domain.[2]

P2TP2A-LIP adalah salah satu lembaga layanan perempuan dan anak yang dirancang untuk memenuhi informasi dan kebutuhan di bidang pendidikan, kesehatan, ekonomi, politik, hukum, perlindungan dan pencegahan kekerasan terhadap perempuan dan anak serta perdagangan manusia. Dibentuk sesuai dengan Keputusan Gubernur Lampung Nomor : G/3456/B.VIII/HK/2002,tentang pembentukan pengurus P2TP2A. Kajian innovation pelayanan publik telah banyak dipelajari oleh berbagai pihak. Penelitian tentang inovasi sering ditemukan dalam perspektif atau pendekatan reformasi birokrasi. Pelayanan publik merupakan bagian dari upaya perbaikan atau mereformasi birokrasi. Semangat reformasi inilah yang pada akhirnya melahirkan inovasi sektor publik. Jika innovation banyak ditemukan di sektor privat sebagai upaya pelayanan prima kompetitif, maka inovasi kini juga hadir di sektor publik. Bersama-sama membuat innovation yang memberikan kemudahan dan kecepatan dalam pelayanan publik kepada masyarakat.[3] Peningkatan pelayanan publik adalah salah satu reformasi birokrasi peningkatan pelayanan masyarakat. Kuliatas pelayanan publik yang terjadi masih kurang maksimal, hal ini dapat dilihat berdasarkan banyaknya pengaduan masyarakat terhadap kualitas pelayanan publik yang diajukan secara langsung kepada unit pelayanan publik dan petugasnya. [4]

Sebagai salah satu sarana pelayanan publik, P2TP2A belum menerapkan teknologi informasi untuk memberikan pelayanan, yaitu pengelolaan pengaduan masyarakat, pengelolaan informasi, pelayanan konsultasi, dan penguluhan kepada masyarakat. Sistem pada P2TP2A sebelumnya masih bersifat konvensional dalam proses pengelolaan pengaduan masyarakat, maka perlu diketahui seberapa besar penerimaan sistem baru berbasis teknologi informasi pada masyarakat dan pegawai di P2TP2A dalam menggunakan aplikasi web engineering agar dapat berfungsi secara maksimal. Web engineering pelayanan pengaduan masyarakat adalah sebuah aplikasi yang memanfaatkan Teknologi Informasi sebagai alat dukung pemerintah dalam memberikan kemudahan-kemudahan pelayanan publik kepada masyarakat.

Penelitian ini bertujuan untuk menganalisis penerimaan aplikasi web engineering pelayanan pengaduan masyarakat menggunakan pendekatan Technology Acceptance Model (TAM). Metode Technology Acceptance Model (TAM) merupakan metode yang mempunyai kontribusi tinggi dalam monitoring implementasi Information Technology (IT). Pada pendekatan technology acceptance model (TAM) terdapat beberapa faktor yang dinilai yaitu persepsi kegunaan atau manfaat dan persepsi kemudahan penggunaan yang didapat dari hasil kuesioner yang diberikan ke responden.[5] Hasil dari penelitian ini akan menunjukkan faktor yang mempengaruhi penerimaan serta bagaimana penerimaan masyarakat terhadap aplikasi web engineering pelayanan pengaduan masyarakat pada P2TP2A.

Suaidah, et.,al (Analisis Penerimaan Aplikasi Web Engineering Pelayanan Pengaduan Masyarakat Menggunakan Technology Acceptance Model) 
Berdasarkan penelitian sebelumnya menggunakan pendekatan penelitian kuantitatif. Metode ini digunakan untuk mengetahui efektifitas aplikasi pengaduan online berbasis web di Fira Informatika dalam melayani pengaduan konsumen. Dari penelitian ini memperoleh hasil analisis setelah melakukan pengujian menggunakan Uji Kolmogorov-Smirnov. Hasil uji hipotesis menunjukkan bahwa nilai rata-rata pengaduan adalah 168.900 yang menunjukkan bahwa aplikasi pengaduan ini efektif menangani pengaduan konsumen, sedangkan sisanya 150.2.600 menunjukkan ukuran rata-rata pengaduan manual.[6] Berdasarkan penelitian lainnya menerapkan pengujian terhadap 30 responden yang menggunakan Technology Acceptance Model (TAM) menemukan bahwa 86\% pengguna setuju bahwa media pembelajaran bermanfaat, $85 \%$ pengguna setuju bahwa media mudah digunakan, $86 \%$ pengguna setuju bahwa mereka berniat menggunakan media tersebut, dan $78 \%$ pengguna menyatakan keraguannya tentang penggunaan media 3D Silat.[7]

Berdasarkan penelitian lainnya menjelaskan bahwa terdapat 8 faktor yang mempengaruhi penerimaan pengguna pada aplikasi E-KRS menggunakan pendekatan TAM. Faktor menjadi konstruk model, konstruk model merupakan rancangan interface, kemampuan dan kemampuan pengunaan, organisasi resources, persepsi tentang kemudahan penggunaan (perceived ease of use), persepsi terhadap kemanfaatan (perceived usefulness), sikap penggunaan (attitude toward using), perilaku untuk tetap menggunakan (behavioral intention to use) dan kondisi nyata penggunaan sistem (actual system usage).[8]

Berdasarkan penelitian lainnya menjelaskan diantara enam hipotesis yang diajukan, lima hipotesis diterima ( $\mathrm{H} 1, \mathrm{H} 2, \mathrm{H} 3, \mathrm{H} 4, \mathrm{H} 6)$, dan satu hipotesis (H5) ditolak. Meskipun pengguna telah memahami dan merasakan manfaat dari aplikasi e-learning namun hal itu tidak mempengaruhi keinginan mereka untuk menggunakan aplikasi. Hal ini dapat terjadi karena meskipun seorang user merasa bahwa manfaat e-learning ini akan membantunya dalam menyelesaikan urusan studi ,namun karena pemanfaatan e-learning tersebut bersifat mandatori menyebabkan user tidak memiliki minat untuk tetap menggunakannya.[9]

Berdasarkan penelitian lainnya menjelaskan hasil dari penelitiannya yaitu dari 11 hipotesis yang telah diuji menggunakan Technology Acceptance Model (TAM) menemukan 6 hipotesis yang memiliki pengaruh antar strukturnya, yaitu: pengaruh rancangan portal terhadap persepsi kemudahan penggunaan (PEOU), pengaruh organisasi e-resources terhadap persepsi kegunaan (PU), pengaruh persepsi kemudahan menggunakan (PEOU) terhadap persepsi kegunaan (PU), pengaruh persepsi kegunaan terhadap sikap kearah penggunaan (ATU), pengaruh persepsi kegunaan terhadap niat untuk menggunakan (BITU) dan pengaruh niat untuk menggunakan (BITU) terhadap penggunaan nyata S-IT (ASU).[10]

\section{METODE PENELITIAN}

\subsection{Kerangka penelitian}

Tahapan penelitian adalah kegiatan penelitian yang dilakukan secara terencana, terstruktur dan sistematis untuk mencapai tujuan tertentu. Tahap penelitian ini juga merupakan perluasan dari kerangka penelitian dan terbagi dalam beberapa sub menu, tahapan penelitian dapat dilihat pada Gambar 1. 


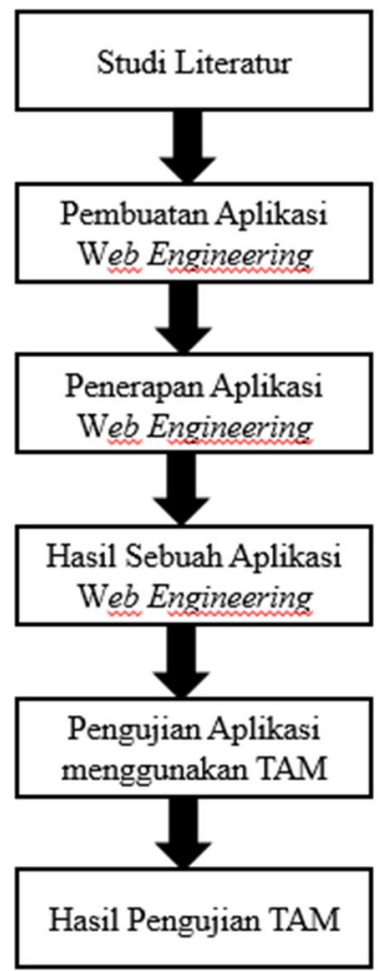

Gambar 1. Kerangka penelitian

\subsection{Metode Pengembangan Sistem}

Web engineering adalah rekayasa web yang menyelaraskan rekayasa perangkat lunak dengan konsep dasar yang menekankan kegiatan teknis dan manajemen. Pengembangan sistem bertujuan untuk menyusun sistem baru baik untuk menggantikan sistem lama secara keseluruhan atau untuk memperbaiki sistem yang ada. Metode web engineering terdiri dari beberapa tahap yaitu perencanaan, perancangan, pemograman, dan pengujian.[11]

Berikut ini penjelasan tiap tahap web engineering yaitu:

\section{A. Perencanaan}

1. Pada tahap ini dilakukan kajian pustaka yang mengacu dari beberapa karya ilmiah. Kajian literatur dari beberapa jurnal dan Buku. Selanjutnya tahap ini dilakukan analisis terhadap kebutuhan - kebutuhan yang akan digunakan untuk membangun sistem. Kebutuhan fungsional dan non fungsional adalah Identifikasi faktor - faktor penunjang untuk kelancaran sistem yang akan dibangun.

2. Kebutuhan Sistem yang diusulkan

a) Kebutuhan Sistem Fungsional

Kebutuhan fungsional merupakan kebutuhan secara kegunaan sistem yang akan diajukan, dimana sistem yang diajukan harus memiliki dan menjawab kebutuhan masalah yang ada saat ini, diantaranya adalah:

1. Menampilkan menu login

2. Menampilkan halaman menu beranda atau menu utama

3. Menampilkan halaman pengaduan masyarakat

4. Menampilkan halaman list pengaduan masyarakat

5. Menampilkan halaman tanggapan pengaduan 
6. Menampilkan halaman list tanggapan pengaduan

7. Menyediakan menu logout

b) Kebutuhan Sistem Non-Fungsional

Kebutuhan Non-Fungsional mendeskripsikan jenis kebutuhan perangkat keras yang dimiliki oleh sistem. Spesifikasi perangkat keras yang digunakan adalah:

1. Perangkat Lunak (Software)

Adapun spesifikasi perangkat lunak (Software) yang digunakan dalam penelitian ini yaitu:

a. Sistem operasi Microsoft Windows 10 profesional

b. MySQL sebagai Database

c. PHP sebagai Bahasa pemograman

d. Web Browser: Mozilla Firefox, Google Chrome, Opera dan Sejenisnya

2. Perangkat Keras (hardware)

Adapun spesifikasi perangkat keras (hardware) yang digunakan dalam penelitian ini yaitu:

a. Processor Intel Core i3

b. Memory $4 \mathrm{~GB}$

c. Hardisk $500 \mathrm{~GB}$

d. Monitor 14 inc

e. Keyboard dan Mouse

B. Perancangan

Perancangan menggunakan objek oriented yaitu menggunakan UML (Unified Modeling Language). Perancangan sistem pada tahapan ini, maksudnya agar mempermudah dalam pembuatan sistem nantinya, sehingga gambaran apa yang akan dibuat jelas maksud dan tujuannya.

C. Pemograman

Pemograman web ini menggunakan Bahasa pemograman php dan database mysql.

D. Pengujian

Skenario pengujian aplikasi yang dibuat menggunakan TAM (Technology Acceptance Model). TAM (Technology Acceptance Model) merupakan suatu model penerimaan sistem teknologi informasi yang akan digunakan oleh pemakai. Pada pendekatan TAM (Technology Acceptance Model) terdapat beberapa faktor yang dinilai yaitu persepsi kegunaan atau manfaat dan persepsi kemudahan penggunaan yang didapat dari hasil kuesioner yang diberikan ke responden. Kegunaan persepsian (perceived usefulness) dan kemudahan penggunaan persepsian (perceived ease of use) keduanya mempunyai pengaruh ke niat perilaku (behavioral intention). Kemudahan penggunaan persepsian (perceived ease of use) mempengaruhi kegunaan persepsian (perceived usefulness).[5] 


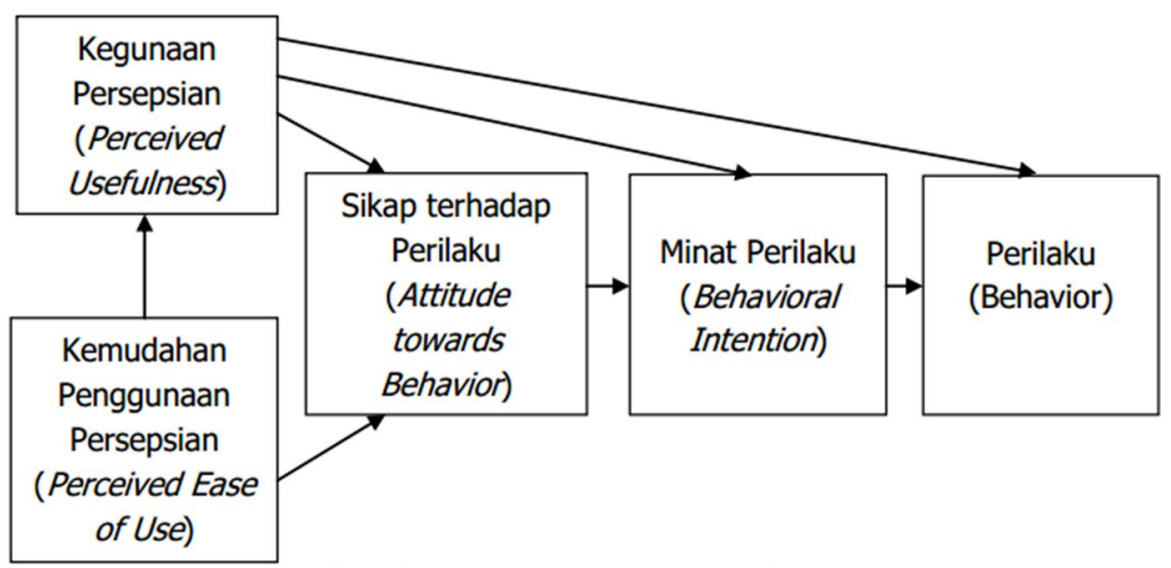

Gambar 2. Skema TAM [5]

\section{HASIL DAN PEMBAHASAN}

\subsection{Model Diagram Usecase}

Berikut adalah Use Case Perancangan Sistem pengaduan pelayanan masyarakat P2PTP2A Provinsi Lampung. Dapat dilihat pada gambar 3. 
SISTEM PENGADUAN PELAYANAN MASYARAKAT P2PTP2A PROVINSI LAMPUNG

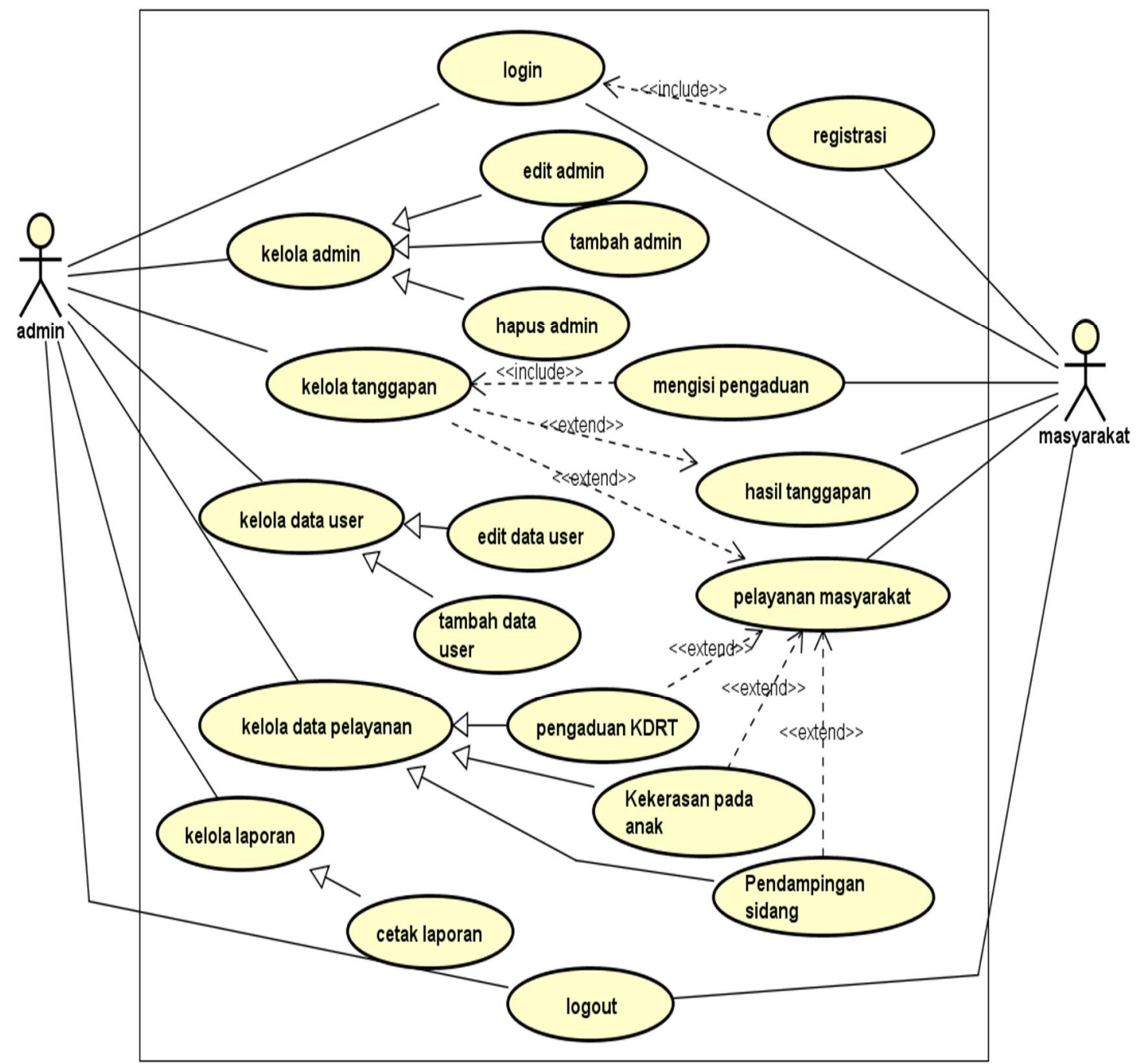

Gambar 3. Diagram Use Case

\subsection{Implementasi}

Implementasi merupakan tahap penerapan dari desain yang telah dirancang ke dalam kode program, implementasi yang dilakukan meliputi implementasi rancangan antar muka (user interface).Sesuai dengan perancangan antarmuka yang sudah dibuat, maka hasil implementasi rancangan interface adalah sebagai berikut:

a) Tampilan Login User

Tampilan login merupakan tampilan ketika sistem akan dijalankan, login harus dilakukan pengguna untuk masuk ke dalam sistem. Berikut tampilan login dapat dilihat pada gambar 4. 


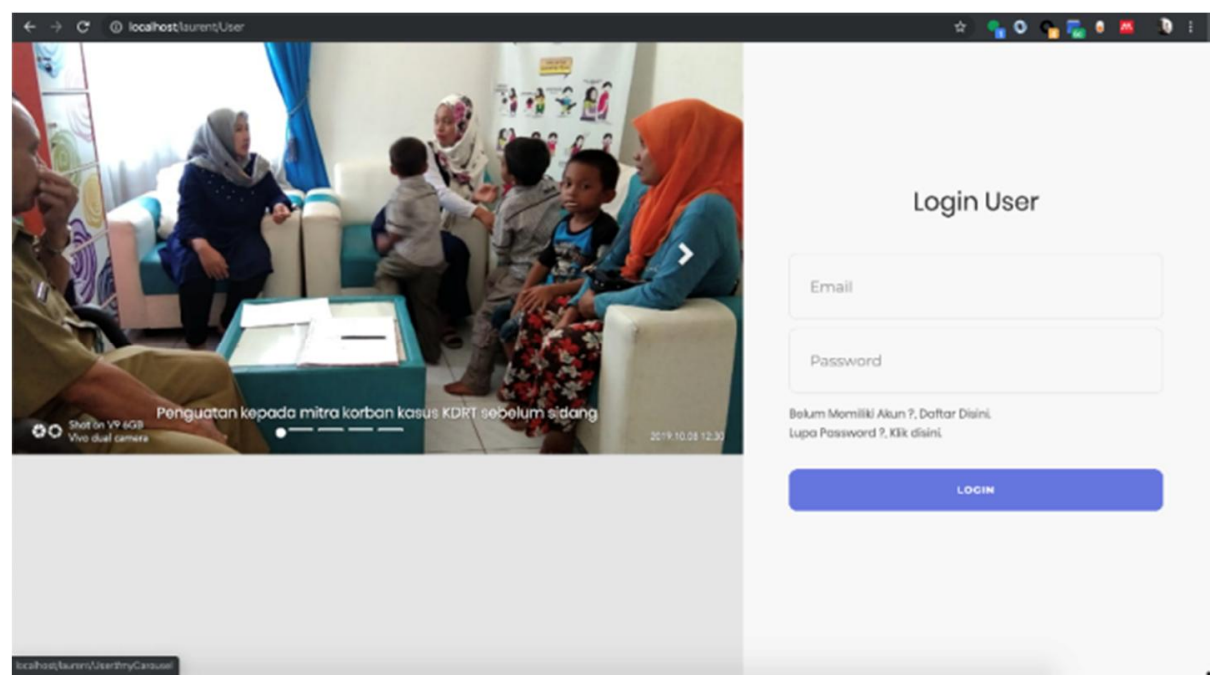

Gambar 4. Tampilan Login User

\section{b) Tampilan Registrasi}

Tampilan registrasi merupakan tampilan sistem untuk mendaftarkan user agar peserta memiliki akun dan dapat hak akses dalam sistem. Berikut tampilan registrasi dapat dilihat pada gambar 5.

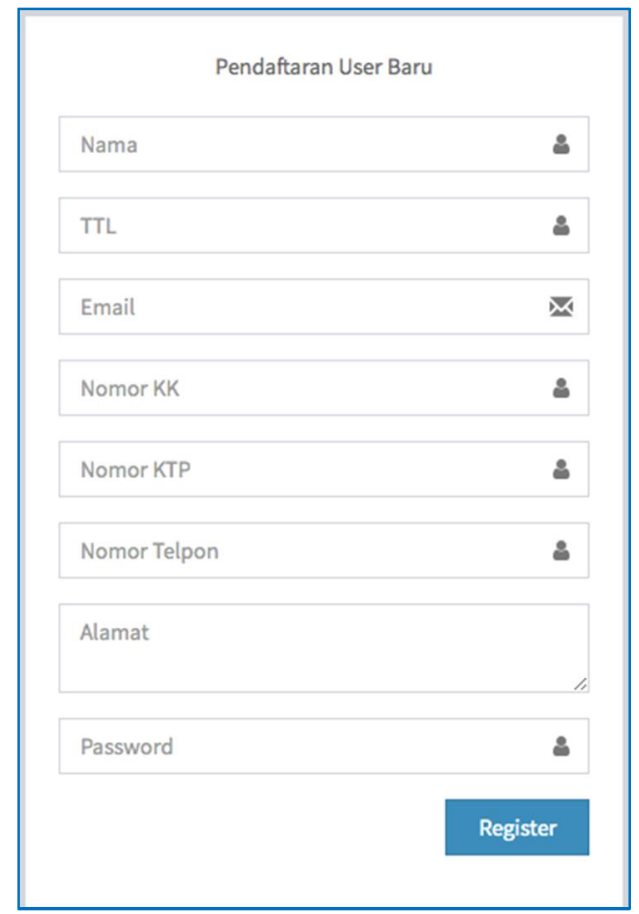

Gambar 5. Tampilan Registrasi

\section{c) Tampilan kronologi}

Tampilan kronologi menampilkan penginputan pengaduan yang diinputkan oleh user sesuai dengan jenis pelayanan yang dibutuhkan oleh user. Berikut adalah tampilan kronologi dapat dilihat gambar 6 . 


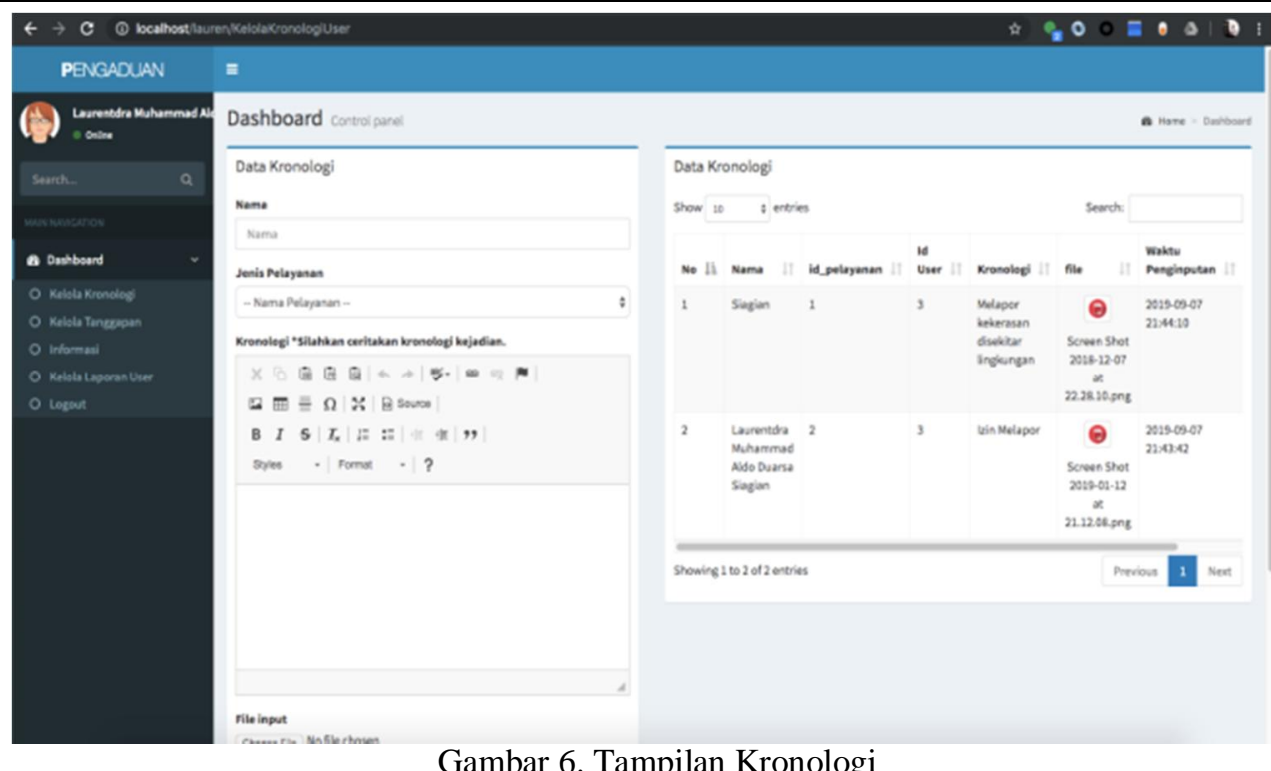

Gambar 6. Tampilan Kronologi

\section{d) Tampilan Tanggapan User}

Tampilan tanggapan user menampilkan list kronologi pelayanan dan tanggapan untuk tindak lanjut pemrosesan masalah. Berikut adalah tampilan data kronologi dapat dilihat pada gambar 7.

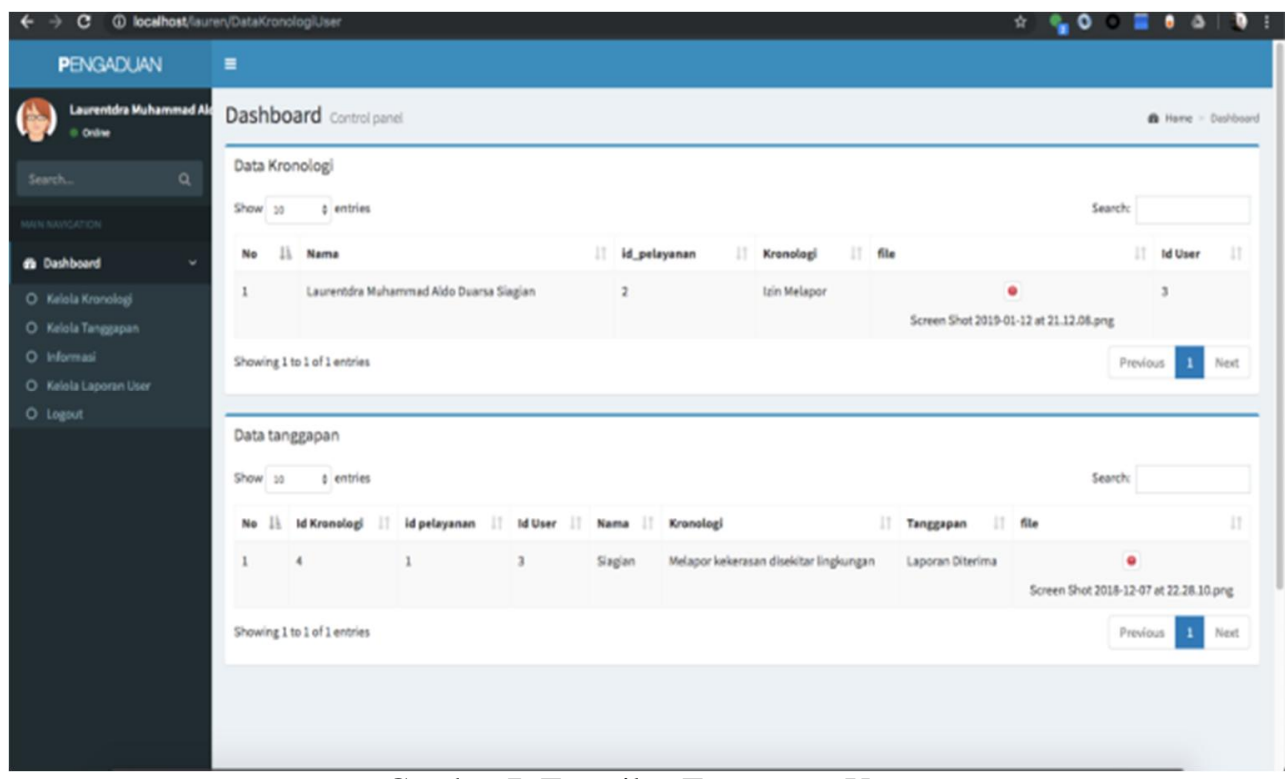

Gambar 7. Tampilan Tanggapan User

\subsection{Kuesioner}

Kuesioner yang dibuat untuk melakukan pengujian ini didasarkan pada 12 indikator penerimaan teknologi yang dijadikan satu butir pertanyaan untuk tiap indikatornya. Butir pertanyaan didapat berdasarkan sumber dari Davis (1989) yang disesuaikan dengan penelitian. Jenis instrumen kuesioner yang digunakan adalah checklist, dalam penelitian ini pihak yang terlibat adalah peneliti, pengurus P2TP2A dan masyarakat. 
Tabel 1. Tanggapan Responden Berdasarkan Persepsi Kegunaan

\begin{tabular}{|c|c|c|c|c|c|c|c|c|}
\hline \multirow{3}{*}{$\begin{array}{l}\text { Kriteria } \\
\text { Jawaban }\end{array}$} & \multirow{3}{*}{ Bobot } & \multicolumn{6}{|c|}{ Persepsi Kegunaan } & \multirow{3}{*}{ Total } \\
\hline & & \begin{tabular}{|c} 
Mempercepat \\
pekeraan
\end{tabular} & \begin{tabular}{|c|}
$\begin{array}{c}\text { Meningkatkan } \\
\text { Kinerja }\end{array}$ \\
\end{tabular} & \begin{tabular}{|c|} 
Meningkatkan \\
Produktifitas \\
\end{tabular} & Efektifitas & \begin{tabular}{|c|} 
Mempermudah \\
Pekeraan
\end{tabular} & Bermanfaat & \\
\hline & & 1 & 2 & 3 & 4 & 5 & 6 & \\
\hline SS & 7 & 23 & 25 & 15 & 25 & 17 & 22 & 889 \\
\hline ST & 6 & 17 & 10 & 17 & 10 & 20 & 20 & 564 \\
\hline CS & 5 & 10 & 12 & 18 & 11 & 11 & 8 & 350 \\
\hline RG & 4 & 0 & 3 & 0 & 4 & 2 & 0 & 36 \\
\hline CTS & 3 & 0 & 0 & 0 & 0 & 0 & 0 & 0 \\
\hline TS & 2 & 0 & 0 & 0 & 0 & 0 & 0 & 0 \\
\hline STS & 1 & 0 & 0 & 0 & 0 & 0 & 0 & 0 \\
\hline \multicolumn{2}{|c|}{ Jumlah Responden } & 50 & 50 & 50 & 50 & 50 & 50 & \\
\hline \multicolumn{2}{|c|}{ Skor Aktual } & 313 & 307 & 297 & 306 & 302 & 314 & 1839 \\
\hline \multicolumn{2}{|l|}{ Skor Ideal } & 350 & 350 & 350 & 350 & 350 & 350 & 2100 \\
\hline
\end{tabular}

Setelah melakukan perhitungan skor pada kegunaan diperoleh nilai variabel sebesar $=1839$. Perhitungan Persentase skor aktual berdasarkan table data tanggapan responden berdasarkan persepsi kegunaan, yaitu persentase penerimaan $=88 \%$. Dari data tanggapan responden berdasarkan persepsi kegunaan, total skor aktual sebesar 1839, sedangkan range skor ideal sangat setuju yaitu 2100 dan skor ideal setuju yaitu 1800, sehingga dapat $88 \%$ responden setuju bahwa aplikasi web engineering pelayanan pengaduan masyarakat pada P2TP2A memiliki kegunaan atau bermanfaat. Secara grafis persentase kriteria kegunaan digambarkan pada Gambar 8.

\section{Persepsi Kegunaan}

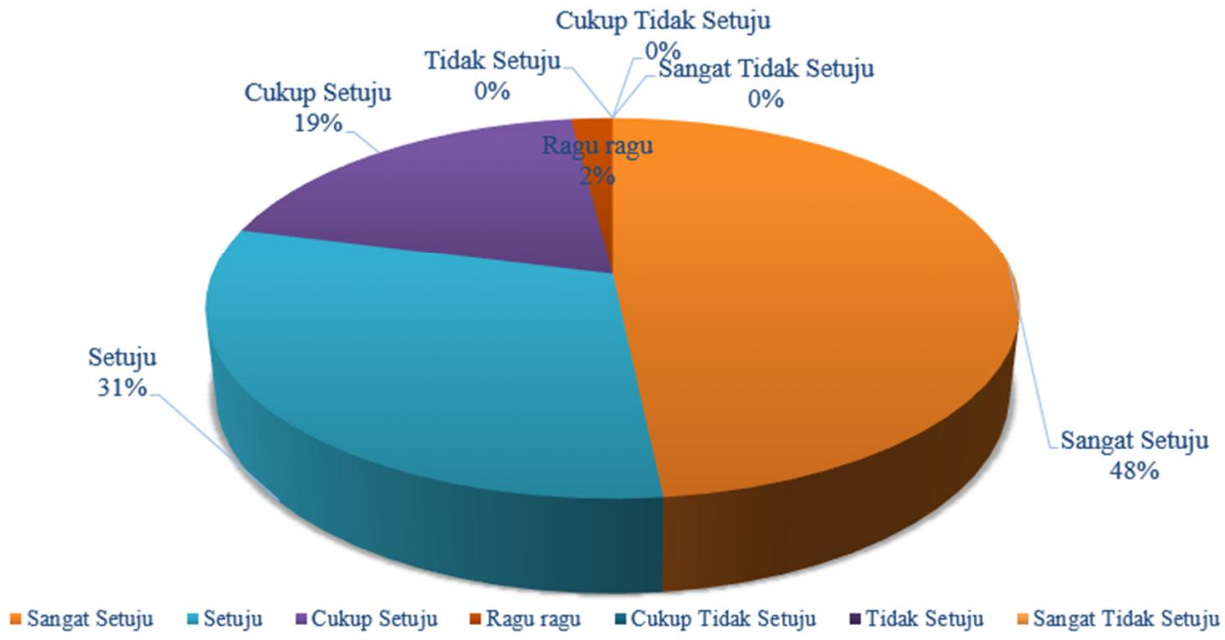

Gambar 8. Pie Chart Kegunaan

Kemudian hasil tanggapan responden berdasarkan persepsi kemudahan dapat dilihat pada tabel 2. 
Tabel 2. Tanggapan Responden Berdasarkan Persepsi Kemudahan Penggunaan

\begin{tabular}{|c|c|c|c|c|c|c|c|c|}
\hline \multirow{3}{*}{$\begin{array}{c}\text { Kriteria } \\
\text { Jawaban }\end{array}$} & \multirow{3}{*}{ Bobot } & \multicolumn{6}{|c|}{ Persepsi Kemudahan Penggunaan } & \multirow{3}{*}{ Total } \\
\hline & & \multirow{2}{*}{\begin{tabular}{|c|}
$\begin{array}{c}\text { Mudah } \\
\text { dipelajari }\end{array}$ \\
7 \\
\end{tabular}} & \multirow{2}{*}{\begin{tabular}{|c|}
$\begin{array}{c}\text { Mudah } \\
\text { dikendalikan }\end{array}$ \\
$\mathbf{8}$ \\
\end{tabular}} & \multirow{2}{*}{$\begin{array}{c}\begin{array}{c}\text { Mudah } \\
\text { dipahami }\end{array} \\
9\end{array}$} & \multirow{2}{*}{$\begin{array}{c}\text { Fleksibel } \\
10 \\
\end{array}$} & \multirow{2}{*}{$\begin{array}{c}\begin{array}{c}\text { Mudah } \\
\text { terampil }\end{array} \\
11\end{array}$} & \multirow{2}{*}{$\begin{array}{c}\begin{array}{c}\text { Mudah } \\
\text { digunakan }\end{array} \\
12 \\
\end{array}$} & \\
\hline & & & & & & & & \\
\hline SS & 7 & 10 & 8 & 9 & 12 & 17 & 11 & 469 \\
\hline ST & 6 & 22 & 26 & 19 & 25 & 23 & 28 & 858 \\
\hline $\mathrm{CS}$ & 5 & 8 & 12 & 20 & 11 & 5 & 8 & 320 \\
\hline RG & 4 & 7 & 3 & 1 & 1 & 5 & 2 & 76 \\
\hline CTS & 3 & 1 & 1 & 1 & 1 & 0 & 1 & 15 \\
\hline TS & 2 & 1 & 0 & 0 & 0 & 0 & 0 & 2 \\
\hline STS & 1 & 1 & 0 & 0 & 0 & 0 & 0 & 1 \\
\hline \multicolumn{2}{|c|}{ Jumlah Responden } & 50 & 50 & 50 & 50 & 50 & 50 & \\
\hline \multicolumn{2}{|l|}{ Skor Aktual } & 276 & 287 & 284 & 296 & 302 & 296 & 1741 \\
\hline \multicolumn{2}{|l|}{ Skor Ideal } & 350 & 350 & 350 & 350 & 350 & 350 & 2100 \\
\hline
\end{tabular}

Setelah melakukan perhitungan skor pada kemudahan penggunaan diperoleh nilai variabel sebesar $=1741$. Perhitungan Persentase skor aktual berdasarkan tabel data tanggapan responden berdasarkan persepsi kegunaan, yaitu persentase penerimaan $=83 \%$. Dari data tanggapan responden berdasarkan persepsi kegunaan, total skor aktual sebesar 1741, sedangkan range skor ideal sangat setuju yaitu 2100 dan skor ideal setuju yaitu 1800, sehingga dapat $83 \%$ responden setuju bahwa aplikasi web engineering pelayanan pengaduan masyarakat pada P2TP2A mudah digunakan. Secara grafis persentase kriteria kemudahan penggunaan digambarkan pada Gambar 9.

\section{Kemudahan Penggunaan}

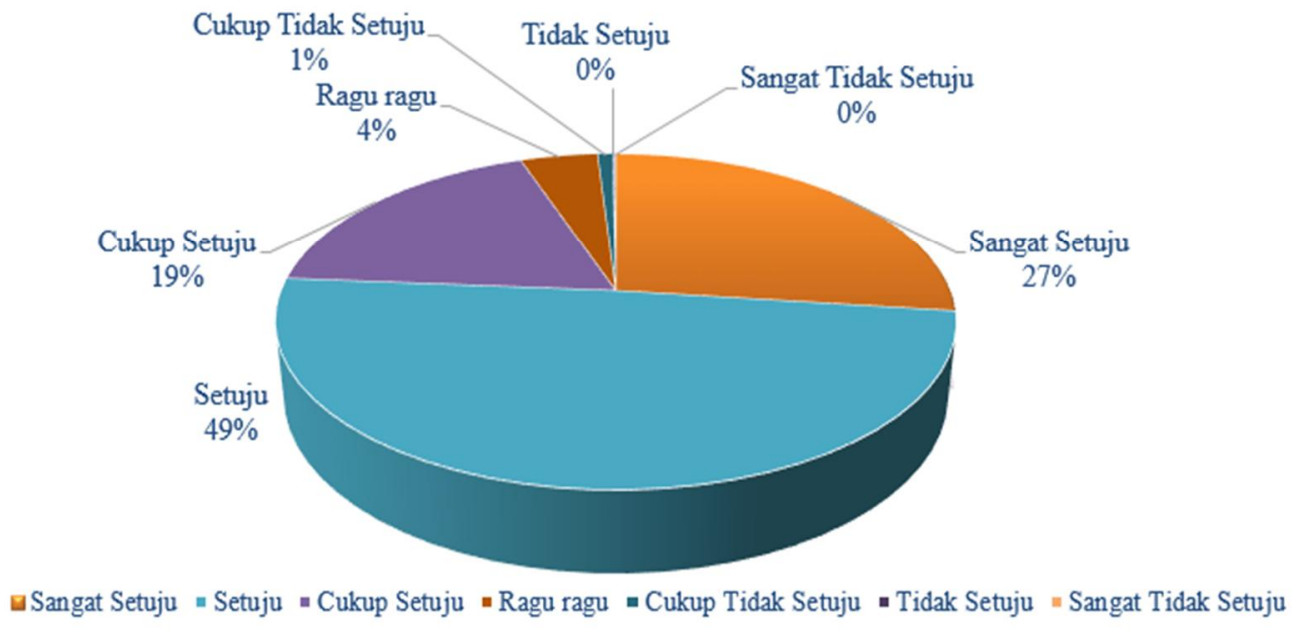

Gambar 9. Pie Chart Kemudahan Penggunaan 


\section{KESIMPULAN}

Berdasarkan hasil pengujian aplikasi web engineering pelayanan pengaduan masyarakat pada P2TP2A dari sisi penerimaan teknologi dengan menggunakan Technology Acceptance Model (TAM) didapatkan hasil bahwa $88 \%$ pengguna setuju bahwa aplikasi web engineering pelayanan pengaduan masyarakat memiliki kegunaan atau bermanfaat, kemudian 83\% pengguna setuju bahwa aplikasi web engineering pelayanan pengaduan masyarakat tersebut mudah untuk digunakan, selanjutnya $88 \%$ pengguna sudah berniat untuk menggunakan aplikasi web engineering pelayanan pengaduan masyarakat secara intens, dan $6 \%$ pengguna masih merasa ragu untuk sungguh-sungguh menggunakann aplikasi web engineering pelayanan pengaduan masyarakat.

\section{SARAN}

Perlu adanya penelitian selanjutnya yang dapat mengembangkan fitur yang terdapat pada aplikasi ditambah profil mengenai layanan yang aktif sehingga memudahkan penggunaan aplikasi dalam mengetahui apakah pengaduan sudah terkirim.

\section{UCAPAN TERIMA KASIH}

Terima kasih, penelitian ini dibiayai oleh DRPM Direktorat Jenderal Penguatan Riset dan Pengembangan Kementerian Riset, Teknologi, dan Pendidikan Tinggi tahun pelaksanaan 2020.

\section{DAFTAR PUSTAKA}

[1] M. Yazdi. 2012, Pelayanan Terpadu Satu Atap (Palu), Vol. 2012, No. Semantik, pp. 450-457,

[2] A. Meliyanti, M. Juliandi, and R. Shella. 2013, Website Monitoring Pelayanan Penyewaan Kapal Angkutan Barang PT. Payung Samudra Dengan Metode UML Based Web Engineering ( UWE ), No. April, pp. 13-21.

[3] I. Hadi, K. Asworo, L. Taqwa Sihidi. 2020, Inovasi Dialogis: Menuju Transformasi Pelayanan Publik yang Partisipatif (Kajian Sistem Pelayanan Malang Online), J. Gov. Civ. Soc., Vol. 4, No. 1, pp. 115-129.

[4] C. Firmansyah and C. Tohir. 2018, Sistem Layanan Pengaduan Masyarakat Lingkup Desa Gunungtanjung Berbasis Web dan SMS Gateway Dengan Metode Antrian Fifo 1, J. Manaj. dan Tek. Inform., Vol. 01, No. 01, pp. 201-210, [Online]. Available: http://jurnal.stmik-dci.ac.id/index.php/jumantaka/article/download/283/371.

[5] F. D. Davis. 1989, Perceived Usefulness, Perceived Ease of Use, and User Acceptance of Information Technology, MIS Q. Manag. Inf. Syst., Vol. 13, No. 3, pp. 319-339, doi: $10.2307 / 249008$. 
[6] A. Pramono. 2014, Sistem Pelayanan Pengaduan Online Berbasis Web pada Agus Pramono, Sist. Pelayanan Pengaduan Online Berbas. Web Pada Pt.Fira Inform. Untuk Meningkat. Layanan Konsum., pp. 1-6.

[7] Y. Rahmanto and R. Y. Utama, 2018, Penerapan Teknologi Web 3D Berbasis Android Sebagai Media Pembelajaran Gerakan Dasar Silat, J. TAM (Technology Accept. Model., Vol. 9, No. 1, pp. 7-14, [Online]. Available: http://ojs.stmikpringsewu.ac.id/index.php/JurnalTam/article/view/593.

[8] R. K. Wiyati. 2014, Analisis Awal Penerimaan Aplikasi E-Krs Menggunakan Pendekatan Tam (Technology Acceptance Model), Konf. Nas. Sist. dan Inform. 2014;, pp. 2-6,

[9] F. S. Rahayu, D. Budiyanto, and D. Palyama. 2017, Analisis Penerimaan E-Learning Menggunakan Technology Acceptance Model (Tam) (Studi Kasus: Universitas Atma Jaya Yogyakarta), J. Terap. Teknol. Inf., Vol. 1, No. 2, pp. 87-98, doi: 10.21460/jutei.2017.12.20.

[10] A. Mulyani and D. Kurniadi. 2015, Analisis Penerimaan Teknologi Student Information Terminal (S-IT) Dengan Menggunakan Technology Acceptance Model (TAM), J. Wawasan Ilm., Vol. 7, No. 12, pp. 23-35.

[11] L. Marlinda and A. Hamid. 2014, Sistem Informasi Budi Daya Jamurmenggunakan Metode Web Engineering, Semin. Nas. Sains dan Teknol. 2014, No. November, pp. 1-4. 